\title{
Boron-Containing Conjugates of Natural Chlorophylls
}

\author{
Mikhail A. Grin, ${ }^{a}{ }^{@}$ Dmitry I. Brittal, ${ }^{a}$ Aleksander G. Tsiprovskiy, ${ }^{a}$ \\ Vladimir I. Bregadze, ${ }^{\mathrm{b}}$ and Andrey F. Mironov ${ }^{\mathrm{a}}$ \\ ${ }^{a}$ M.V. Lomonosov Moscow State Academy of Fine Chemical Technology, 119571 Moscow, Russia \\ ${ }^{\mathrm{b}}$ A.N. Nesmeyanov Institute of Organoelement Compounds of Russian Academy of Sciences, 119991 Moscow, Russia \\ @Corresponding author E-mail: michael_grin@mail.ru
}

\begin{abstract}
Boron neutron capture therapy (BNCT) is binary method for the treatment of cancer, which is based on the nuclear reaction of two essentially nontoxic species, nonradioactive ${ }^{10} B$ and low energy thermal neutrons. The neutron capture reaction by ${ }^{10} \mathrm{~B}$ produces high-linear-energy transfer ions ${ }^{4} \mathrm{He}^{2+}$ and ${ }^{7} \mathrm{Li}^{+}$that dissipate their kinetic energy during traveling one cell diameter (5-9 $\mu \mathrm{m})$ in biological tissues, giving them the potential for precise cell-killing. Efficient $B N C T$ requires selective accumulation of ${ }^{10} B$ atoms in cancer cells. Since tetrapyrrole compounds have a unique property of being selectively accumulated in tumor tissues, they have attracted attention as agents for both the targeted delivery of boron clusters to tumor cells and the combined PDT-BNCT therapy, which would undoubtedly enhance the efficiency of antitumor therapy. From this point of view, chlorin based photosensitizers with intense near IR absorption are of particular interest. Chlorins are photosensitizers that have high quantum yields of singlet oxygen production and absorb light in the 640-690 $\mathrm{nm}$ region, i.e. within the so-called 'phototherapeutic window' (630-900 nm), where light absorption and scattering in human tissues are minimized and they are relatively transparent for activating light. In this contribution we describe the synthesis of conjugates of natural chlorins and bacteriochlorins with closo-dodecaborate and cobaltbis(dicarbollide) anions. In the present work, the Sonogashira reaction, the 'click' methodology, which are actively employed in modern organic chemistry were used for the synthesis of boron-containing conjugates of natural chlorins and bacteriochlorins.
\end{abstract}

Keywords: Chlorophyll $a$, chlorin, bacteriochlorin, purpurin, photodynamic therapy, boron neutron capture therapy of cancer.

\section{Борсодержащие производные природных хлорофиллов}

\author{
М. А. Грин, ${ }^{a}$ А. И. Бриттал, ${ }^{a}$ А. Г. Ципровский, ${ }^{a}$ В. И. Брегадзе, ${ }^{b}$ А. Ф. Миронов ${ }^{\mathrm{a}}$ \\ ${ }^{\mathrm{a}}$ Московская Государственная академия тонкой химической технологии им. М.В. Ломоносова, 119571 Москва, \\ Россия \\ ${ }^{\mathrm{b}}$ Институт элементоорганических соединений им. А.Н. Несмеянова РАН, 119991 Москва, Россия \\ @E-mail: michael_grin@mail.ru
}

\begin{abstract}
В настоящеем обзоре рассмотрены пути синтеза конъюгатов борных полиэдров с природными ди- $u$ тетрагидропорфиринали и показана перспективность некоторых из них для борнейтронозахватной терапии рака.
\end{abstract}

Ключевые слова: Хлорофилл а, хлорин, бактериохлорин, пурпурин, фотодинамическая терапия, борнейтронозахватная терапия рака.

\section{Введение}

Борнейтронозахватная терапия (БНЗТ) рака является новым бинарным методом терапии в онкологии. В основе метода лежит взаимодействие борсодержащих соединений, способных селективно накапливаться в опухоли, с потоком тепловых нейтронов, в результате которого образуются высоко реакционноспособные $\alpha$-частицы, разрушающие раковые клетки. ${ }^{[1-6]}$ БНЗТ позволяет удалять глубокозалегающие опухоли, например, глиомы мозга, когда традиционные методы лечения, включая хирургический метод, химио- и лучевую терапии, оказываются неэффективны. Для успешного внедрения этого метода в клиническую онкологию 
необходимо решить ряд задач, связанных с созданием борсодержащих препаратов, разработкой медицинской аппаратуры для доставки нейтронного излучения к опухоли, вопросы дозиметрии и др. Серьезной проблемой при использовании соединений бора в БНЗТ является отсутствие туморотропности борных кластеров, в связи с чем возможно распределение их по всем органам и тканям.

К настоящему времени синтезирован и изучен ряд борсодержащих аналогов биологически активных веществ, среди которых аминокислоты, полиамины, пептиды, сахара, липиды, нуклеиновые кислоты и фрагменты антител. ${ }^{[7,8]}$ Биологические исследования полученных конъюгатов показали повышение тропности последних к опухолевым клеткам.

Способность порфиринов селективно накапливаться в опухолевой ткани позволяет наряду с фотодинамической терапией (ФДТ) использовать их в качестве транспортных систем для доставки соединений бора в опухоль. ${ }^{[9-12]} \mathrm{C}$ этой точки зрения особый интерес представляют фотосенсибилизаторы на основе природных хлорофиллов с интенсивным поглощением в ближней ИК-области спектра, что позволяет использовать лазерное облучение, проникающее в глубоко расположенные слои пораженной ткани. ${ }^{[13-18]}$

В настоящем обзоре рассмотрены пути синтеза конъюгатов борных полиэдров с природными ди- и тетрагидропорфиринами, реализованные в Московской Государственной академии тонкой химической технологии им. М.В. Ломоносова, совместно с Институтом элементоорганических соединений им. А.Н.Несмеянова PAН, проанализированы результаты биологических испытаний полученных конъюгатов и показана перспек- тивность некоторых из них для борнейтронозахватной терапии рака.

Для реализации связывания таких лабильных объектов, как хлорины и бактериохлорины, с борными кластерами нами были использованы реакции, отвечающие определенным требованиям, главные из которых - это мягкие условия проведения реакций и высокие выходы целевых продуктов. В качестве таких реакций были выбраны:

- 1,3-диполярное циклоприсоединение терминальных алкинов с азидами в присутствии солей одновалентной меди;

- Рd-катализируемая реакция образования С-С связей между арил- или винилгалогенидами и терминальными алкинами;

- реакция нуклеофильного раскрытия 1,4-диоксанового кольца в оксониевых производных субстратов.

Среди соединений бора перспективными кандидатами на роль борных фрагментов в конъюгатах для БНЗТ были выбраны полиэдрические соединения бора - производные клозо-додекаборат аниона $\left[\mathrm{B}_{12} \mathrm{H}_{12}\right]^{2-}$ и аниона бис(дикарболлид)кобальта $\left.\quad\left[3,3 \text { '-Co(1,2- } \mathrm{C}_{2} \mathrm{~B}_{9} \mathrm{H}_{11}\right)_{2}\right]^{-}$. Характерной особенностью данных полиэдров является образование стабильных заряд-компенсированных оксониевых производных, раскрытие 1,4-диоксанового цикла в которых широко используется для присоединения различных нуклеофилов. ${ }^{[19-20]}$

\section{Результаты и обсуждение}

Общая стратегия синтеза конъюгатов на основе производных хлорофилла $a$ и бактериохлорофилла $a$ представлена на Рисунке 1.

\section{Вариант 1}

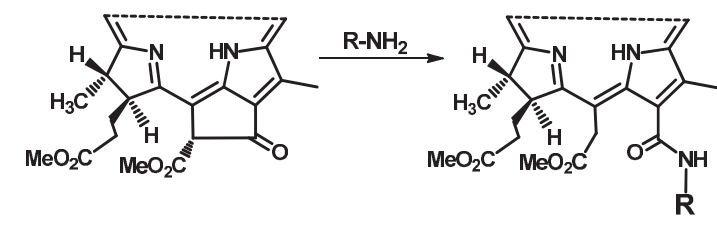

Вариант 2
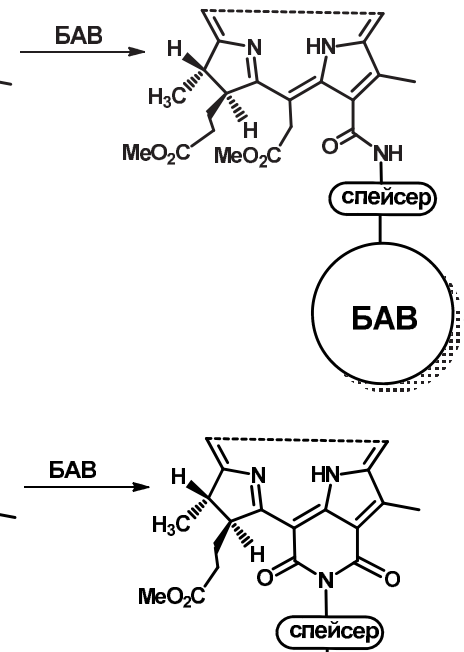

БAB
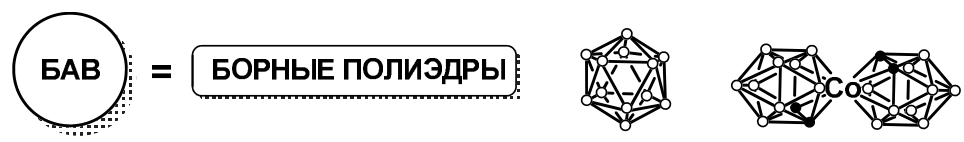

$\mathrm{OBH}$

Рисунок 1. Методы синтеза конъюгатов. 
Первый вариант включает нуклеофильное раскрытие циклопентанонового кольца в метилфеофорбиде $a$ и региоселективное образование $13^{1}$-амидов. В качестве нуклеофилов использовали алкилдиамины и пропаргиламин, получая таким образом пигменты с терминальными аминогруппой и тройной связью.

Ключевыми соединениями во втором варианте синтеза являлись пурпурин 18 и бактериопурпурин, на основе которых были получены циклические имиды с якорными группами для присоединения борных кластеров.

\section{Реакция 1,3-диполярного ичиклоприсоединения в синтезе борсодержащих конъюгатов в ряду хлорофилла а}

Реакция циклоприсоединения [3+2] между азидами и алкинами с терминальной тройной связью универсальна ${ }^{[21-23]}$ и используется для создания сложных биоконъюгатов, иммобилизации биомолекул на матрицах различной природы и присоединения лекарств к адресным системам доставки. ${ }^{[24] ~ Ш и р о к о м у ~ п р и м е н е н и ю ~}$ вышеописанной реакции для нужд биологической и фармацевтической химии способствовало значительное увеличение ее скорости за счет использования соединений $\mathrm{Cu}^{\mathrm{I}}$ в качестве катализатора. Кроме того, последний способствует региоселективному протеканию реакции с образованием 1,4-дизамещенных 1,2,3-триазолов. ${ }^{[25]}$

В качестве ключевого соединения в синтезе хлоринового конъюгата был использован метилфеофорбид $a$ 1, из которого с выходом 86\% получено производное хлорина $e_{6}$ с терминальной тройной связью 2 (Рисунок 2). ${ }^{[26]}$

Хлорин 2 конденсировали с азидами, полученными путем раскрытия азидом натрия диоксанового кольца в оксониевых производных клозо-додекабората $\left[\mathrm{O}\left(\mathrm{CH}_{2} \mathrm{CH}_{2}\right)_{2} \mathrm{O}-\mathrm{B}_{12} \mathrm{H}_{11}\right] \mathbf{4}$ и бис(дикарболлид)кобальта
[8-O $\left.\left(\mathrm{CH}_{2} \mathrm{CH}_{2}\right)_{2} \mathrm{O}-3,3^{\prime}-\mathrm{Co}\left(1,2,-\mathrm{C}_{2} \mathrm{~B}_{9} \mathrm{H}_{10}\right)\left(1^{\prime}, 2^{\prime}-\mathrm{C}_{2} \mathrm{~B}_{9} \mathrm{H}_{11}\right)\right]$ 5. Реакция циклоприсоединения проводилась в присутствии 10 мол. \% иодида меди(I). В течение первых 10 мин. происходило образование $\mathrm{Cu}$-комплекса хлорина, сопровождающееся гипсохромным смещением длинноволновой полосы поглощения пигмента с 663 до 635 нм. $^{[27]}$

Поэтому в дальнейшем нами был реализован иной подход к синтезу борсодержащих конъюгатов, основанный на использовании Zn-комплекса амида 3. Было показано, что $\mathrm{Zn}$-комплекс хлорина $e_{6}$ с терминальной тройной связью (3) в условиях реакции является достаточно устойчивым и не подвергается замещению на ион меди. После деметаллирования продуктов реакции были получены конъюгаты 8 и 9 с выходами 60\% и 68\%, соответственно.

Биологические испытания полученных конъюгатов, выполненные на клетках аденокарциномы легкого человека A549, показали, что внутриклеточная концентрация соединений 8 и 9 недостаточна для эффективного фотодинамического разрушения клеток, что ограничивает использование подобных конъюгатов в ФДТ и БНЗТ рака. ${ }^{[28,29]}$

\section{Реакиия Соногаширы в синтезе борсодержаших хлоринов}

Особый интерес среди реакций, используемых для получения конъюгатов тетрапиррольных соединений с молекулами других классов, представляет палладий катализируемая реакция образования С-С связи между арилгалогенидами и терминальными алкинами ${ }^{[30-32]}$ в присутствии солей меди(I) в качестве сокатализатора (реакция Соногаширы). ${ }^{[33]}$

Нами получены новые борсодержащие конъюгаты на основе алкинилированного кобальт бис(дикарболлид) аниона и $n$-иодфенильных производных хлорина $e_{6}$ и
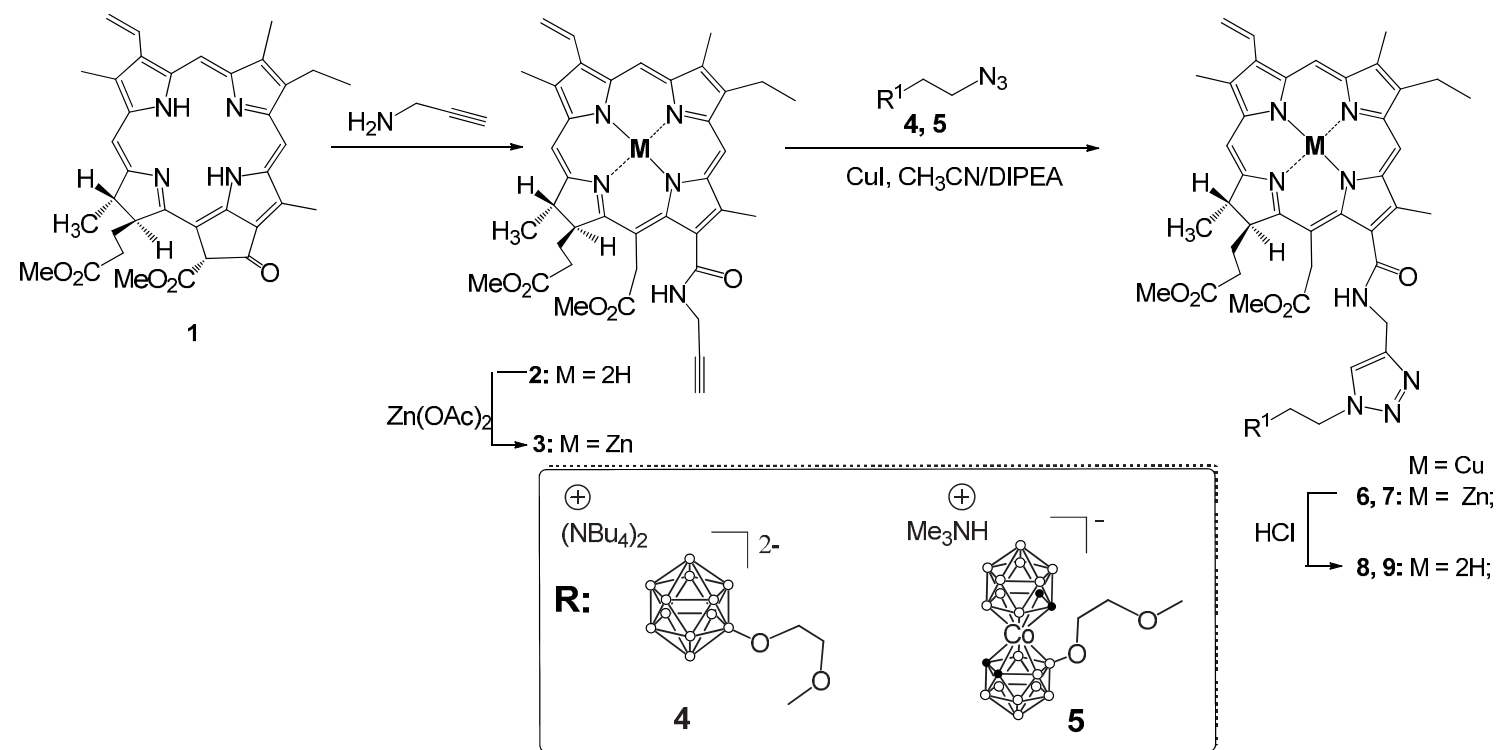

Рисунок 2. Синтез борсодержащих конъюгатов методом 1,3-диполярного циклоприсоединения. 

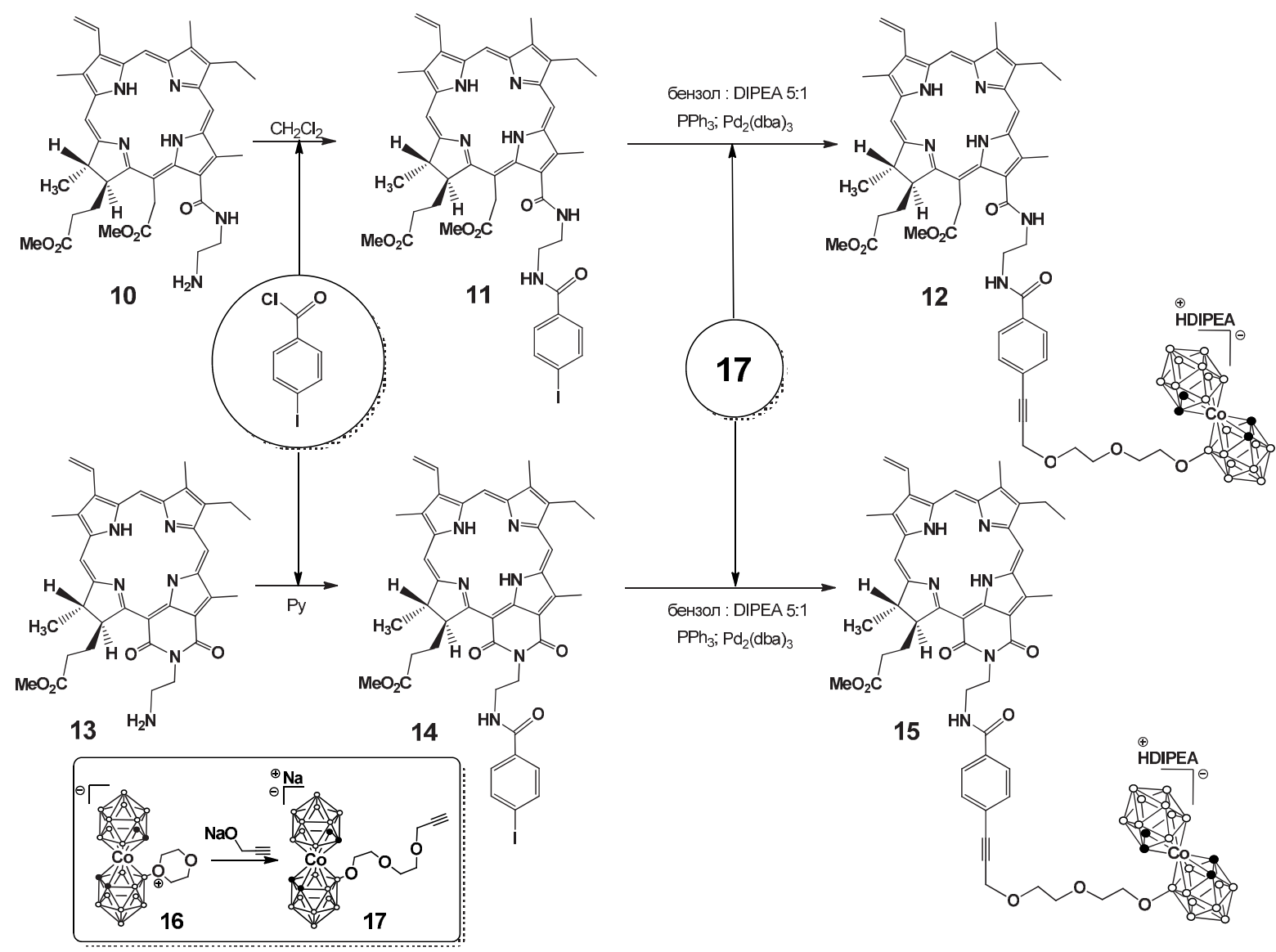

Рисунок 3. Получение борсодержащих конъюгатов на основе производных хлорофилла $a$ по реакции Соногаширы.

пурпуринимида по реакции Соногаширы (Рисунок 3). [34] Борную субъединицу 17 , содержащую концевую ацетиленовую группу, связанную с борным полиэдром гибким гидрофильным спейсером, получали действием 2-пропин-1-илата натрия на оксониевое производное бис(дикарболлид) кобальта 16. Хлориновые компоненты для реакции Соногаширы в виде $n$-иодфенильных производных 11 и 14 получали ацилированием аминосодержащих хлоринов 10 и 13 хлорангидридом $n$-иодбензойной кислоты. Реакцию проводили в атмосфере аргона в смеси бензола и диизопропилэтиламина в соотношении 5:1 в течение 48 часов. В качестве катализатора использовали трис(дибензилиденацетон) дипалладий(0) с трифенилфосфином. Для предотвращения возможности встраивания иона меди в хлориновый макроцикл был реализован вариант реакции Соногаширы без солей $\mathrm{Cu}$. Конъюгаты 12 и 15 получены с выходами 61\% и 69\%, соответственно, и их структура подтверждена спектральными характеристиками. ${ }^{[34]}$

Борсодержащие конъюгаты 12 и 15 являются гидрофобными соединениями. Они хорошо растворяются в органических растворителях и не растворимы в воде. Для исследования этих конъюгатов in vitro при приготовлении растворов был использован биологически совместимый солюбилизатор Кремофор EL (CrEL), который обеспечивает в водных растворах стабилизацию мономерной формы гидрофобных тетрапиррольных соединений. ${ }^{[35,36]}$
Способность хлорина $e_{6}$ флуоресцировать в красной области спектра в составе конъюгатов позволяет использовать флуоресцентную микроскопию для изучения взаимодействий соединений 12 и 15 с раковыми клетками. Методом лазерной сканирующей конфокальной микроскопии установлено, что конъюгаты проникают в клетки A549 аденокарциномы легкого человека и накапливаются в цитоплазме. При этом в обоих соединениях наблюдается сходное внутриклеточное распределение концентрирование в гранулярных клеточных структурах субмикронного размера. При этом они не проникают в ядро клетки и не накапливаются в плазматической мембране. Оказалось, что конъюгаты 12 и 15 обладают низкой фотоиндуцированной цитотоксичностью, однако выполняют свою основную задачу - доставляют в раковые клетки кластеры бора, необходимые для БНЗТ.

\section{Борсодержашчие конъюгаты в ряду бактериохлорофилла а}

Нами разработан новый метод синтеза борсодержащих конъюгатов в ряду бактериохлорофилла $a$ с использованием в качестве ключевого соединения $N$-аминобактериопурпуринимида $\quad \mathbf{1 8} .^{[37]}$ Переход к бактериопроизводным связан с созданием ИК-фотосенсибилизаторов, поглощающих в области 800 нм для реализации сочетанной ФДТ-БНЗТ, что должно повысить эффективность воздействия на опухоль. 


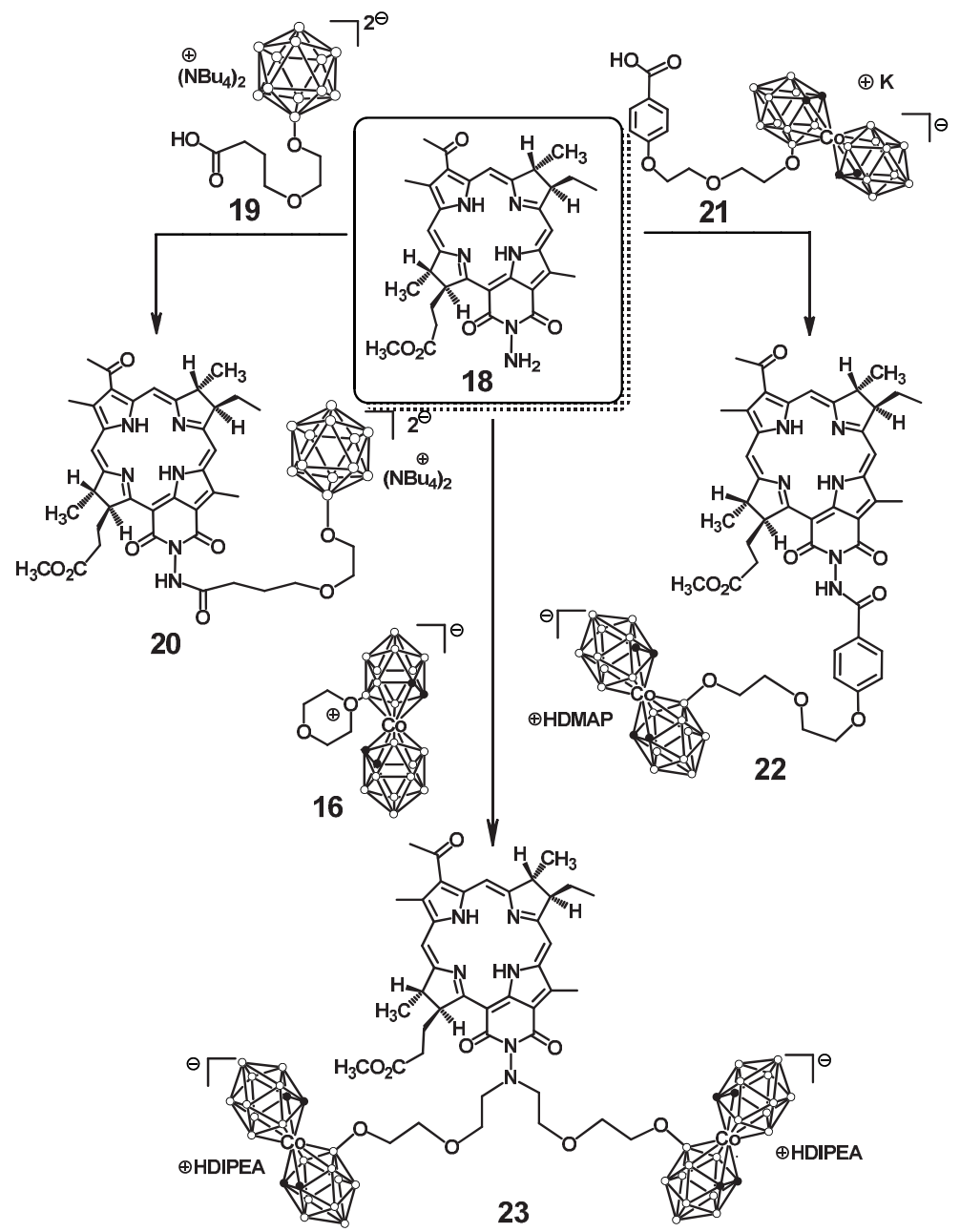

Рисунок 4. Синтез конъюгатов $N$-аминобактериопурпуринимида с борными полиэдрами.

Наличие экзоциклической аминогруппы в циклоимиде 18 позволило разработать два пути синтеза конъюгатов, один из которых включал создание СO-NH связи между макроциклом и борными кластерами, а другой заключался в присоединении металлокарборана 16 путем раскрытия диоксанового цикла в нем (Рисунок 4).

Первый подход был реализован за счет взаимодействия циклоимида 18 с карборанилкарбоновыми кислотами, используя различные методы активации карбоксильной группы. Конъюгат 20 получали, действуя на исходный $N$-аминобактериопурпуринимид 18 хлорангидридом додекаборатсодержащей карбоновой кислоты 19 в присутствии триэтиламина, ${ }^{[38]}$ в то время как конъюгат 22 был получен в результате взаимодействия того же циклоимида 18 с кислотой 21, активированной дициклогексилкарбодиимидом. ${ }^{[39]}$

Однако такой способ синтеза борсодержащих конъюгатов позволил получить целевые продукты с выходами, не превышающими 20\%. Более эффективным оказался подход, включающий нуклеофильное раскрытие цикла в оксониевом производном бис(дикарболлид)кобальта 16 в присутствии DIPEA. Конъюгат 23, содержащий два борных полиэдра и поглощающий при 830 нм, был получен с высоким выходом и является перспективным соединением для проведения медико-биологических испытаний.

\section{Выводы}

Разработана методология получения конъюгатов природных хлоринов с борными полиэдрами, включающая использование современных методов органического синтеза. Предложенные подходы к синтезу вышеназванных конъюгатов включают приготовление прекурсоров на основе природных дии тетрагидропорфиринов, с одной стороны, и борных кластеров, с другой стороны, и последующее их сочетание в мягких условиях реакции с достаточно высокими выходами целевых продуктов. Впервые получены борсодержащие конъюгаты на основе производных бактериохлорофилла $a$, в том числе содержащие большое количество атомов бора, что позволяет рассматривать их в качестве перспективных фотосенсибилизаторов для комбинированной ФДТ и БНЗТ рака.

\section{Список литературы}

\section{References}

1. Hawthome M.F. Angew. Chem. Int. Ed. Engl. 1993, 32, 950-984.

2. Barth R.F., Goderre J.A., Vicente M.G.H., Blue T.E. Clin. Cancer. Res. 2005, 11, 3987-4002. 
3. Vitale A.A, Hoffmann G., Pomilio A.B. Mol. Med. Chem. 2005, 8, 1-49.

4. Bregadze V.I., Sivaev I.B., Glazun S.A. Anti-Cancer Agents Med. Chem. 2006, 6, 75-109.

5. Yinghuai Z., Yan K.C., Maguire J.A., Hosmane N.S. Curr. Chem. Biol. 2007, 1, 141-149.

6. Sivaev I.B., Semioshkin S.A., Bregadze V.I. Eur. J. Inorg. Chem. 2009, 1433-1450.

7. Soloway A.H., Tjarks W., Barnum B.A., Rong F.-G., Barth R.F., Codogni I.M., Wilson J.G. Chem. Rev. 1998, 98, 1515-1562.

8. Sivaev I.B., Bregadze V.I. Eur. J. Inorg. Chem. 2009, 14331450 .

9. Haushalter R.C., Rudolph R.W. J. Am. Chem. Soc. 1978, 100, 4628-4629.

10. Haushalter R.C., Butler W.M., Rudolph R.W. J. Am. Chem. Soc. 1981, 103, 2620-2627.

11. Evstigneeva R.P., Zaitseev A.V., Luzgina V.N., Ol'shevskaya V.A., Shtil A.A. Curr. Med. Chem. - Anti-Cancer Agents, 2003, 3, 383-392.

12. Renner M.W., Miura M., Easson M.W., Vicente M.G.H. AntiCancer Agents Med. Chem. 2006, 6, 145-157.

13. Mironov A.F., Grin M.A. J. Porphyrins Phthalocyanines 2008, 12, 1163-1172.

14. Ratajski M., Osterloh J., Gabel D. Anti-Cancer Agents Med. Chem. 2006, 6, 159-166.

15. Luzgina V.N.,Ol'shevskaya V.A.,Sekridova A.V.,Mironov A.F., Kalinin V.N., Pashchenko V.Z., Gorokhov V.V., Tusov V.B., Shtil' A.A. Zh. Org. Khim. 2007, 43, 1245-1253 (in Russ.).

16. Ol'shevskaya V.A., Zaytsev A.V., Savchenko A.N., Shtil' A.A, Cheong C.S., Kalinin V.N. Bull. Korean Chem. Soc. 2007, 28, 1910-1916.

17. Ol'shevskaya V.A., Nikitina R.G., Savchenko A.N., Malshakova M.V., Vinogradov A.M., Golovina G.V., Belykh D.V., Kutchin A.V., Kaplan M.A., Kalinin V.N., Kuzmin V.A., Shtil A.A. Bioorg. Med. Chem. 2009, 17, 1297-1306.

18. Ol'shevskaya V.A., Savchenko A.N., Zaitsev A.V., Kononova E.G., Petrovskii P.V., Ramonova A.A., Tatarskiy V.V., Uvarov O.V., Moisenovich M.M., Kalinin V.N., Shtil A.A. J. Organomet. Chem. 2009, 694, 1632-1637.

19. Sivaev I.B., Semioshkin A.A., Brellochs B., Sjoberg S., Bregadze V.I. Polyhedron 2000, 67, 627-632.

20. Sivaev I.B., Starikova Z.A., Sjoberg S., Bregadze V.I. J. Organomet. Chem. 2002, 649, 1-8.

21. Wang Q., Chan T.R., Hilgraf R., Fokin V.V., Sharpless K.B., Finn M.G. J. Am. Chem. Soc. 2003, 125, 3192-3193.

22. Chen Q., Yang F., Du Y. Carbohydr. Res. 2005, 340, 24762482.
23. Link A.J., Tirrell D.A. J. Am. Chem. Soc. 2003, 125, 1116411165.

24. Kolb H.C., Sharpless K.B. Drug Discovery Today 2003, 8, 1128-1137.

25. Bock V.D., Hiemstra H., Maarseveen J.H. Eur. J. Org. Chem. 2006, 1, 51-68.

26. Grin M.A., Lonin I. S., Makarov A.I., Lakhina A.A., Toukach F.V., Kachala V.V., Orlova A.V., Mironov A.F. Mendeleev Commun. 2008, 18, 135-137.

27. Grin M.A., Lonin I.S., Lakhina A.A., Ol'shanskaya E.S., Makarov A.I., Sebyakin Y.L., Guryeva L.Yu., Toukach P.V., Kononikhin A.S., Kuzmin V.A., Mironov A.F. J. Porphyrins Phthalocyanines 2009, 13, 336-345.

28. Bregadze V.I., Sivaev I.B., Lobanova I.A., Titeev R.A., Brittal D.I., Grin M.A., Mironov A.F. Appl. Radiat. Isot. 2009, 67, 101-104.

29. Bregadze V.I., Semioshkin A.A., Las'kova J. N., Berzina M.Ya., Lobanova I.A., Sivaev I.B., Grin M.A., Titeev R.A., Brittal D.I., Ulybina O.V., Chestnova A.V., Ignatova A.A., Feofanov A.V., Mironov A.F. Appl. Organomet. Chem. 2009, 23, 370-374.

30. Dieck H.A., Heck F.R. J. Organomet. Chem. 1975, 93, 259263.

31. Cassar L. J. Organomet. Chem. 1975, 93, 253-257.

32. Sonogashira K., Tohda Y., Hagihara N. Tetrahedron Lett. 1975, 16, 4467-4470.

33. Wagner R.W., Ciringh Y., Clausen C., Lindsey J.S. Chem. Mater. 1999, 11, 2974-2983.

34. Grin M.A., Titeev R.A., Brittal D.I., Chestnova A.V., Feofanov A.V., Lobanova I.A., Sivaev I.B., Bregadze V.I., Mironov A.F. Izv. Ross. Akad. Nauk, Ser. Khim. 2010, 1, 215-220 (in Russ.).

35. Feofanov A.V., Grichine A.I., Karmakova T.A., Pljutinskaya A.D., Lebedeva V.S., Filyasova A., Yakubovskaya R.I., Mironov A.F., Egret-Charlier M., Vigny P. Photochem. Photobiol. 2002, 75, 633-643.

36. Feofanov A.V., Nazarova A.I., Karmakova T.A., Pljutinskaya A.D., Grichine A.I., Yakubovskaya R.I., Lebedeva V.S., Ruziyev R.D., Mironov A.F., Maurizot J.-C., Vigny P. Bioorg. Khim. 2004, 30, 417-428 (in Russ.).

37. Mironov A.F., Grin M.A., Tsiprovskiy A.G. J. Porphyrins Phthalocyanines 2002, 6, 358-361.

38. Grin M.A., Semioshkin A.A., Titeev R.A., Nizhnik E.A., Grebenyuk J.N., Mironov A.F., Bregadze V.I. Mendeleev Commun. 2007, 17, 14-15.

39. Grin M.A., Mironov A.F., Bregadze V.I., Sivaev I.B., Titeev R.A., Brittal D.I., Bakieva O. M., Lobanova I.A. Izv. Ross. Akad. Nauk, Ser. Khim. 2008, 10, 2190-2192 (in Russ.). 